\title{
WHAT ARE WE TALKING ABOUT WHEN WE TALK ABOUT CARE? \\ A conceptual review of the literature
}

\author{
José de São José \\ Faculty of Economics, Research Centre for Spatial and Organizational Dynamics, University of \\ Algarve, Faro, Portugal
}

\begin{abstract}
The primary aim of this article is to make a contribution to clarify the concept of "care" in the field of care for older people, by reviewing and discussing the conceptual literature and, based on this, by proposing a new unified definition. The secondary aim of this article is to trace, in general terms, the evolution of the empirical research on care for older people, presenting at the same time, possible avenues for future research. It is expected that a new unified definition of the concept of care may contribute to a better operationalization of it, enhancing the reliability and validity of future research and the potential for comparative analysis and theory development.
\end{abstract}

$\underline{\text { Keywords }}$ care, older people, conceptual review.

Resumo O principal objetivo deste artigo é contribuir para a clarificação do conceito de "cuidar" no domínio dos cuidados para pessoas idosas. Esta clarificação é realizada através da revisão e discussão da literatura conceptual e, com base nessa revisão, também através da proposta de uma nova definição unificadora do conceito de "cuidar". O objetivo secundário deste artigo é traçar, em termos gerais, a evolução da investigação empírica sobre os cuidados prestados a pessoas idosas, apresentando, ao mesmo tempo, possíveis avenidas para a futura investigação. Espera-se que um nova definição unificadora do conceito de "cuidar" possa contribuir para melhorar a sua operacionalização, aumentando a fidedignidade e a validade da futura investigação e o potencial para a análise comparativa e o desenvolvimento teórico.

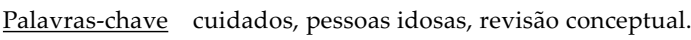

Résumé Le but principal de cet article est de contribuer à la clarification de la notion de "prendre soin" dans le domaine des soins pour les personnes âgées. Cette clarification est réalisée grâce à la revue et à la discussion de la littérature conceptuelle et, sur la base de cette revue, également en proposant une nouvelle définition unificatrice du concept de "prendre soin". L'objectif secondaire de cet article est de décrire en termes généraux, l'évolution de la recherche empirique sur les soins aux personnes âgées, présentant en même temps, les avenues possibles pour la recherche future. Il est prévu qu'une nouvelle définition unificatrice du concept de "prendre soin" peut aider à améliorer son opérationnalisation, ce qui augmente la fiabilité et la validité de la recherche future et le potentiel pour l'analyse comparative et l'élaboration théorique.

Mots-clés soins, personnes âgées, revue conceptuelle.

Resumen El propósito principal de este artículo es contribuir a la clarificación del concepto de "cuidar" en el campo de la atención a las personas mayores. Esta clarificación se lleva a cabo a través de la revisión y discusión de la literatura conceptual y, sobre la base de esta revisión, también mediante la propuesta de una nueva definición unificadora del concepto de "cuidar". El objetivo secundario de este artículo es describir en términos generales, la evolución de la investigación empírica sobre la atención a los mayores, presentando al mismo tiempo, las posibles vías para la investigación futura. Se espera que una nueva definición unificadora del concepto de "cuidar" puede ayudar a mejorar su aplicación práctica, lo que aumenta la fiabilidad y la validez de la investigación futura y el potencial para el análisis comparativo y el desarrollo teórico.

Palabras-clave cuidar, mayores, revisión conceptual. 


\section{Introduction}

Providing and receiving care are central components of social life, as they accompany us over our entire life courses (Barnes, 2012). Most of the English dictionaries define the verb "to care" as "to be concerned" and "to make provision". As we will see later, the literature on care also includes these two components of care. On the other hand, this literature tends to circumscribe care to the realm of social care (e.g. bathing, feeding, dressing), excluding health care. However, the division between social and health care is not always easy to establish, as the borders can be blurred.

Care is nowadays a "burning policy issue in almost every society" (Kröger, 2009: 399), including care for older people due to the challenges raised by the ageing of the population, especially the fear that we may have to face a "caring deficit", i.e., an insufficient number of caregivers to meet the needs of a growing number of dependent older people (Tronto, 2013).

On the other hand, research on care for older people has grown immensely over the past decades (Phillips, 2007) and today is a priority topic for the research funding agencies in most countries of the world (see, for example, the European Union programme called "Horizon 2020").

In the fields of research and policy, it is commonly accepted that care, at the micro level of the reality, has to do with relationships (and in most cases with reciprocity), practical activities, love and affection (associated predominantly to family care), and responsibility (Phillips, 2007). At the macro level of the reality, care has to do with "larger structural questions of thinking about which institutions, people, and practices should be used to accomplish concrete and real caring tasks" (Tronto, 2013: 139).

However, research on care, particularly research on care for older people, has been marked by the use of different definitions of care (James, 1992; Thomas, 1993; Daly and Lewis, 2000; Phillips, 2007; Tronto, 2013). Joan Tronto (2013: 18) underlie that "One of the larger problems for all theorists of care has been to define the term". In turn, Mary Daly and Jane Lewis (2000: 284) stress that " [...] the concept of care is both ambiguous and contested. Part of the problem is that it has been used in such diverse ways that it is in danger of losing its core meaning". For example, some definitions emphasize the emotional nature of care, circumscribe it to the private/domestic sphere and conceive it as a non-waged work. Other definitions emphasize the practical nature of care, establish that care practices can occur both in the private/domestic sphere and in the public sphere, and conceive care not only as non-waged work but also as waged work. This diversity of definitions of care, and the associated operationalisations, produces inevitably a significant divergence in terms of results/findings, making it difficult to make comparisons between studies and compromising the potential for theory development.

The primary aim of this article is to make a contribution to the clarification of the concept of care in the field of elder care, by reviewing and discussing the relevant conceptual literature and, based on this literature review, to propose a unified (and more complex) definition of care which allows the clear identification of its main dimensions and some components within each dimension. Considering that 
it is not easy to separate the discussion of the conceptual literature from the discussion of the empirical literature, it was decided to establish a secondary aim for this article, namely to trace, in general terms, the evolution of the empirical research on care for older people, identifying at the same time possible avenues for future research.

It is expected that a unified definition of the concept of care (in the context of elder care) may contribute to a better operationalization of it, enhancing the reliability and validity of future research and the potential for comparative analysis and theory development. Additionally, it is expected that a broad review of the empirical research on care for older people may be useful to gain and initial introduction to this field of research and to identify new horizons for future studies.

The remaining part of this article is organised as follows: description of the type of literature review undertaken; review and discussion of the relevant literature; proposal for a new unified definition of care; suggestions for future research; final thoughts. It should be noted that "care" is used throughout the article as a synonym for caregiving, caring and care work.

\section{Type of literature review}

There are two main types of literature review, the traditional or narrative review and the systematic review (Jesson, Matheson and Lacey, 2011; Bryman, 2012). A narrative review should be used when the aim is to provide an overview of the literature on a certain topic (Jesson, Matheson and Lacey, 2011; Bryman, 2012). In turn, a systematic review should be used when the aim is to get answers to one or more specific and succinct questions on a certain topic. Considering the aims of this article described earlier, the narrative review appeared to be the most appropriate type of review, particularly the subtype designated by Jesson and collaborators (2011) by "conceptual review". Therefore, the review presented here is a narrative review strongly oriented by the conceptual review subtype.

Contrarily to the systematic reviews, the narrative reviews normally do not specific the methods to identify, appraise and analyse the relevant studies. Accordingly, the selection of the reviewed literature presented here was based on the author's knowledge of the literature on care for older people (the author has been studying this topic for many years).

The presentation and discussion of the review will follow a chronological sequence, starting with the most distant years and ending with the most recent years.

\section{Review of the literature}

\section{The 1980s}

The first proposals to conceptualize the reality of care for older people appeared in the 1980s in Europe and North America. The studies conducted by Janet Finch and 
Dulcie Groves (1983), Jane Lewis and Barbara Meredith (1988), Clare Ungerson (1987), Qureshi and Walker (1989), Elaine Brody (1981), Rhonda Montgomery, Gonyea and Hooyman (1985), Rhonda Montgomery, Stull and Borgatta (1986), and Kari Wærness (1984a, 1984b) contributed greatly to this enterprise. According to these initial proposals, the care relationship was predominantly conceptualized as a unidirectional relationship in which an active and independent caregiver provides care to a passive, dependent and burdensome care-receiver. In this sense, the care relationship was conceived as a dependence relationship ingrained in a power imbalance to the detriment of the care-receiver. Furthermore, caregiving was essentially viewed as doing something to someone who is not able to meet their needs by herself/himself (without the help of other person). In this respect, self-care and care provided to someone who is able to self-care were excluded from the definition of care (see Parker, 1981). The exclusion of these situations has remained relatively unchanged.

Given this understanding of the care relationship, it is not surprising that the first studies on care for older people have been mainly focused on the caregivers and their experiences of providing care, especially the negative experiences (impacts of caregiving on several spheres of the caregivers' lives, such as physical and mental health, finances, social and leisure activities). The experiences and perspectives of the care-receivers were neglected.

Nevertheless, the care researchers selected different social domains to give account of the caregivers' experiences and perspectives. In the North America and United Kingdom they privileged the private domain (family and home), whilst in the Scandinavian countries they privileged the public domain (care workers in the public sector, mainly in the home care services). Consequently, in the first group of countries care was conceptualized, essentially, as a synonym for family caregiving provided at home (an exception of this conceptualization can be found in Parker, 1981 ) and in the second group of countries care was seen as a synonym for formal care (provided within the framework of a formal organization). The different focuses adopted in these two groups of countries were due, largely, to differences in welfare state models (the role of public services in the domain of care for older people was clearly more prominent in the second group of countries).

Family caregiving was conceptualized as containing two essential components, labour and love, that is, activity and positive emotions/meanings: "[...] caring demands both love and labour, both identity and activity [...]" (Graham, 1983: 13-14).

Furthermore, family caregiving was conceptualised as being anchored in family duties and obligations, and with the exception of very few conceptualizations (e.g. Parker, 1981), was understood as uncommodified work (unpaid work). Accordingly, family caregiving was portrayed as the quintessential of care (family caregiving as good care / better care). This dominant perspective was clearly emphasized by Graham (1983: 29):

[...] both carers and their dependents recognize that the substitute services are not "care", since they lack the very qualities of commitment and affection which transform caring-work into a life-work, a job into a duty. 
Finally, family caregiving was predominantly conceptualized as a women's work and a work that forms the women's social identity:

[...] caring is not simply something women do for themselves, to achieve their femininity. It is something women do for others, to keep them alive. (Graham, 1983: 25).

Based on empirical evidence, the prototype of an elder's family caregiver was a woman (mainly a daughter), white, middle-aged, out of the labour market and belonging to the middle-class.

Despite the common interest of the North American and British researchers in capturing the experience of providing family care, they used different theoretical approaches. The North American researchers mobilized mainly the Stress Theories, mainly the conceptual framework developed by Leonard Pearlin (1989) in order to understand how the stress and burden faced by family caregivers affected their health and well-being (however the gendered nature of family caregiving were implicit in many studies). In turn, a strong gender perspective within the Feminist Theories was essential for the British researchers, as their main concern was to demonstrate that, within the family, women were the main providers of care for the dependent elders, that caregiving was socially constructed as a woman's issue, and that this situation has put women in a disadvantaged position in comparison with men.

Regarding the research methods and designs, the studies conducted in North America were mainly quantitative and cross-sectional whilst most of the studies conducted in the United Kingdom were qualitative and also cross-sectional. Nevertheless, in both parts of the world these initial studies neglected the cultural, economic and social contexts under which caregiving were embedded.

As mentioned earlier, in the Scandinavian countries the initial concern was to understand the experiences of the formal care workers rather than the experiences of the family caregivers (in this part of the world, the interest in family/informal caregiving emerged later during the 1990s). In these countries formal care was conceived mainly as labour, although it was recognized that formal care workers may undertake their job with love (in a warm and emotional manner). Kari Wærness (1984a) designated this kind of approach performed by care workers, i.e., caring in a warm manner, as "the rationality of caring". Furthermore, formal care was viewed as being anchored in values and norms beyond those which are present in the context of family life. The prototype of an elder's formal caregiver was a white woman belonging to the working class.

The Scandinavian research on care was also mainly guided by a gender perspective within the Feminist Theories, calling the attention to the disadvantaged position that the female care workers occupied in the labour market. This research was also predominantly qualitative and cross-sectional, paying little attention to the contexts in which formal care was embedded.

Finally, it is important to add that during this decade several kinds of care tasks were identified by different authors, such as Parker (1981), Lewis and Meredith (1988) and Qureshi and Walker (1989). For example, Parker (1981), using the concept of "tending" instead of "care", suggested that the tending tasks include 
feeding, washing, lifting, cleaning up, protecting and comforting. The several kinds of care tasks identified in the 1980s can be organised in the following types: instrumental care (activities of daily living, such as bathing, and feeding, and instrumental activities of daily living, such as shopping and preparing meals), socio-emotional care (e.g. emotional support and keeping company) and supervising/monitoring (e.g. liaising with formal care systems and monitoring the use of medicines). This typology of care tasks was not submitted to significant changes in the subsequent years (for a slightly different typology of care tasks, see Nolan, Grant and Keady, 1996).

\section{The 1990s}

During the 1990s the feminist researchers, mainly in the United Kingdom, recognized the need to redefine the concept of care in order to make it more comprehensive (e.g.: Ungerson, 1990; Graham, 1991, 1997; Arber and Ginn, 1992). It was proposed to take into account other types of caregivers such as male family caregivers, non-kin caregivers, caregivers from different ages and social classes, caregivers belonging to ethnic minorities, working caregivers, etc. Associated to the need of taking into account different types of caregivers, the importance of the contexts (social, cultural, economic, etc.) under which the care relationship takes place was definitely recognised (see Graham, 1991; Arber and Ginn, 1992). Furthermore, a conceptual redefinition took place in order to consider that caregiving may have not only negative, but also positive impacts for the caregiver (see Graham, 1997). It was also proposed the inclusion of the public domain as a domain in which the care relationship can take place, and the practical component of the caregiving was emphasized in order to overcome the triad "caregiving-love-private domain of the family", which made it difficult to discuss care as a public issue (see Ungerson, 1990). Finally, the possibility of waged care work, in both the private/domestic and public domains, was also definitely recognized (see Ungerson, 1990; Graham, 1991).

However, Thomas (1993: 650-651) argued that the re-conceptualizations of care proposed particularly by Graham (1991) and Ungerson (1990) did not solve "[...] the problem of the partial and fragmented character of preceding concepts of care", as none of them was sufficiently comprehensive. In this vein, Thomas (1993: 665) proposed a "unified" concept of care:

Care is both the paid and unpaid provision of support involving work activities and feeling states. It is provided mainly, but not exclusively, by women to both able-bodied and dependent adults and children in either the public or domestic spheres, and in a variety of institutional settings.

Based on this concept, Thomas (1993) identified seven dimensions of care:

- the social identity of the carer (social characteristics which define the carers, such as gender; the roles of the carers, such as the role of wife, daughter, home care worker, etc.); 
- the social identity of the care recipient (social characteristics which define the care recipients, such as the dependency status; the groups to which the care-receivers belong, such as adults, children, older people, etc.);

- the inter-personal relationships between the carer and the care recipient (the nature of the relationship between the caregiver and the care-receiver, such as kinship, friendship, service/professional relationship, etc.);

- the nature of care (the primary social content of care; normally defined as both an activity and a "feeling state");

- the social domain within which the caring relationship is located (private/domestic domain and public domain);

- the economic character of the care relationship (waged or non-waged care work);

- the institutional setting in which care is delivered (physical location of care activities).

The definition proposed by Thomas (1993) was a significant step towards finding a comprehensive definition of care, as she identified several dimensions of the concept. However, curiously, Thomas (1993) left out some dimensions which had already been introduced by others authors, such as the "caregiving tasks" mentioned by several authors in the 1980s, and the "contexts of care" (social, cultural, economic, etc.) mentioned by several authors in the early 1990s. Therefore, the proposal of Thomas (1993) did not prove to be totally unifying.

The debate on care became more heated when the Disability Movement and the disability scholars, especially Jenny Morris $(1995,1997)$ and Lois Keith $(1992)$, produced severe criticism of the care research carried out to date. Based on the Social Model of Disability (see Oliver, 1983), the disability critique argued that the concept of care and the care research was oppressive and objectifying, as it had reduced the disabled (and older) people to the status of mere "dependents" without voice, and favoured the study of the caregiver's experiences and perspectives. In order to counteract this trend, the disability movement and the disability scholars proposed to give voice to the care-receivers and to focus on independence rather than on dependency. They conceptualized independence as choice and control rather than self-sufficiency. The introduction of cash-for-care schemes, such as the direct payments in the United Kingdom (public financial transfers for people needing care), was viewed by the disability activists as a good measure to ensure choice and control over the care arrangements. The focus on independence went hand in hand with a focus on individual human rights.

The debate on care during the 1990s also greatly benefitted from the contributions of care scholars such as Joan Tronto (1993) and Selma Sevenhuijsen (1998), who contributed to the development of a theoretical framework designated by Ethics of Care. This framework argued that all human beings provide and receive care over their life courses and called attention to the political and moral implications of care both at micro and macro levels of reality. The ethics of care framework underlined the relational nature of care, arguing that interdependence, rather than independence, was a better category to understand care. This framework did not deny, 
rather acknowledged, the dependency on both sides of the care relationship. As Marian Barnes (2006) emphasized, the same person can be a caregiver and a care-receiver at the same time and at different times. The ethics of care scholars argued that in a care relationship inherently interdependent, care is a product of the relationship between two or more persons, and the power dynamics are in constant movement and redefinition.

Within the Ethics of Care framework, Tronto proposed one of the most interesting conceptualizations of care. Tronto and Berenice Fisher started by proposing the following broad definition of care:

On the most general level, we suggest that caring be viewed as a species activity that includes everything that we do to maintain, continue, and repair our "world" so that we can live in it as well as possible. That world includes our bodies, our selves, and our environment, all of which we seek to interweave in a complex, life-sustaining web. (Fisher and Tronto, 1991, cit. in Tronto, 1993: 103).

Based on this definition, Tronto (1993) emphasised that care is both a disposition and an activity, that it is inherently relational (evolving two or more persons) and that it is materialized through a complex process. This process includes the following phases: caring about (recognizing unmet needs), taking care of (taking the responsibility to ensure the meeting of needs), caregiving (undertaking concrete actions in order to meet the needs), and care-receiving (responding to the care received). Tronto (1993) completed her conceptualizing work by identifying the ethic elements associated with each phase of the caring process. They are, respectively: attentiveness (being attentive to the unmet needs), responsibility (taking the responsibility for meeting the needs), competence (providing skilful and appropriate care) and responsiveness (responding to the caregivers). The author suggested that "good care" is achieved if the four phases are realized according to the respective ethic elements.

Despite the differences between the disability and the ethics of care perspectives, both were concerned with giving voice to the care-receivers (recognizing their agency) and with promoting their rights. However, the Ethics of Care has become a theoretical tool with a greater popularity within care research.

In the 90s, the trend towards the development of a more comprehensive concept of care was accompanied by a diversification of the research topics, theoretical frameworks and research methods. In addition to the understanding of the caregivers' experiences in different social contexts, taking into account distinct social domains and sectors of care (private and public; informal and formal), and structures such as social class and ethnicity, many other strands of research emerged or gained a new impetus. Among these are the decision-making process of caregiver selection within the family (punctuated by the notions of flexibility, negotiation and opportunity costs, taken from the Feminist Theories and Rational Choice Theory), the reconciliation between work and care (dominated by the notion of conflict roles taken from the Role Theory), the articulation between informal and formal care (marked by dichotomies such as substitution-complementary taken, 
respectively, from the Substitution and Complementary Models), etc. The last two strands gained a considerable impetus due to the significant increase of the female participation in the labour market and the changes in the welfare sates which were particularly visible during the 1990s in the western world.

It is also during the 90s that the debate on care was definitively positioned also at the macro level of the reality. This had to do with the changes in most of the welfare states of the western world towards a welfare mix in the domain of care for older people (diversification of the provision of care by different care sectors). Several studies on the social division of care were conducted, aimed at capturing the division of responsibilities, in terms of provision and financing, between several sectors, such as the state, the family, the market and the community (voluntary sector). Many of these studies, initiated by the pioneering work of Anelli Anttonen and Jorma Sipilä (1996) in the field of social policy, aimed to compare the social care regimes of different countries (e.g.: Knijn and Kremer, 1997; Lewis, 1998). Research at this level was mainly guided by the Welfare Regimes framework and have adopted quantitative methods.

\section{The twenty-first century}

Many of the developments in the literature on care for older people which occurred during the 1990s have been consolidated over the twenty-first century, especially the recognition that the care relationship is based on interdependency/reciprocity, that this relationship may have both negative and positive impacts for caregivers and care-receivers, that the full understanding of this relationship requires paying attention to the wider contexts in which it is embedded (contexts of different nature and different level of proximity), that care needs to be linked to citizenship (right for care and to care), and that care relationships lie at the intersection of dichotomies such as public-private, informal-formal, unpaid-paid.

However, other developments initiated in the 1990s were extended to new domains. For example, at the macro level of reality, the literature on the social division of care became interested in the globalization of care. On one hand, the interest focused on the division of care provision between countries and, on another hand, focused on the migration of people, mainly women, from the developing countries to provide care for children and dependent adults in the developed countries, leaving behind, in many cases, their own children and dependent adults. The number of studies on migrant caregiving increased significantly during the last decade (see Zechner, 2008; Kong, Deatrick and Evans, 2010; Christensen and Guldvik, 2014). These new global arrangements of care raise again the issue of the gender division of care, as well as the issue of social exclusion.

During the twenty-first century, we also saw the emergence of some new conceptual developments and new research topics. The conceptual developments derived from a new criticism from the part of the disability scholars against the concept of care, leading them to propose alternative concepts, such as "help", "support" and "assistance". Yet, the proposals for new concepts have not been put 
forward only from the side of the disability scholars. The care scholars have also reworked the concept of care. For example, Mary Daly and Jane Lewis (2000), proposed the concept of "social care" with the purpose to definitely overcome the dichotomies that have fragmented the concept of care, such as public-private, informal-formal, paid-unpaid. Daly and Lewis (2000) argued that social care lies at the intersection of these dichotomies and suggested that this concept may be used to analyse the reality of care both at the micro and macro levels. They defined three dimensions for the concept: care as labour/work, a form of work that is carried out under certain conditions; care as an activity located within a normative framework of obligation and responsibility; and care as an activity with costs, both financial and emotional, which cross the public/private boundaries.

In turn, Julia Twigg and collaborators (2011), conceptualized care work as "body work", called our attention to the body as the central object of care work. Finally, Tronto (2013) recognised that the definition of care proposed by herself and Fisher in the 90s (Fisher and Tronto, 1990, cit. in Tronto, 1993: 103) is a broad definition, but from her viewpoint this is not a problem because more narrow definitions of care can be formulated by simple specifying the contexts in which care is deployed. The specification of these contexts can be done, according to Tronto (2013), by identifying the purpose of care (e.g. promoting independence, alleviating physical pain) and the power dynamics involved in the care relationship (Who has more power? Who is in command?). In more recent years, the disability and care scholars have converged in several aspects (Kröger, 2009), putting forward proposals that make the bridge between the two perspectives, such as the New Political Ethic of Care proposed by Fiona Williams (2004).

Concerning the new research topics which definitely emerged over the last decade and a half, there are some that already have a significant volume of studies while others begun to be studied only more recently. As examples of the first group of topics we have the ambivalence in care dynamics (contradictory dispositions and feelings in interpersonal relationships, in the decision-making process of caregiver selection, in the reconciliation between work and caregiving, etc.), and the abuse/neglect of older people in different care settings (despite the fact that an awareness of elder abuse in the context of family life first appeared in the mid-1970s, it began to be the subject of systematic empirical research only in the early 2000s). In addition, it is worth mentioning the topic of integrated care (integrating social care and health care) and the topic of the care-receivers' experiences and perspectives of receiving care. Interestingly, despite the fact that the disability and care scholars had recognized, in the 1990s, that it was essential to give voice to the recipients of care, it was only in the 2000s that researchers began to give them this opportunity (São José et al., 2015). In turn, dignity in care, and information and communication technologies and care, are some examples of the group of topics which begun to be studied more recently. The project Futurage (The University of Sheffield, 2011), which produced a road map for future research on ageing, also identified long term care as a relevant topic to be studied in a more consistent way. 


\section{A new unified definition of care}

As we had the opportunity to verify, the literature on care has developed greatly over the last 35 years. In the 80 s, the care relationship was conceived as a dependent relationship, in which the care-receiver is dependent on the caregiver. The main research concern was to account for the negative experiences of the caregivers, especially the female caregivers, neglecting the experiences of the care-receivers. Since then, there have been successive redefinitions of the concept of care in order to make it more comprehensive and more balanced, accounting for the interdependent dynamics between the caregivers and care-receivers, the different types of caregivers operating in different care domains and sectors, and the practices, processes and social representations of care both at the micro and macro levels of reality.

However, the problem of conceptual fragmentation was not completely solved, as there is still no unified concept of care which is comprehensive, consensual and stabilized. The conceptual work developed by Thomas (1993) was a major attempt to create a unified definition of care. Nevertheless, as mentioned earlier, some dimensions of the concept previously identified by other authors are absent in the conceptualization proposed by Thomas. Since then, there have been other contributions to clarify the concept, being those proposed by Tronto (1993, 2013) and Daly and Lewis (2000) of special relevance, but these contributions have not been combined with each other and with the contribution made by Thomas (1993). Furthermore, there are other important dimensions of care which have been neglected by the successive conceptualisations of care. These are the "caregiving approach" (the manner/way through which care is provided) and the "foundations of care" (the rationale for providing care; the reasons to provide care). It is suggested that the caregiving approach is an important dimension of care because, as a recent systematic literature review demonstrated, the experiences of receiving care are strongly dependent on the caregivers' attitudes and behaviours toward the care-receivers (São José et al., 2015). In other words, the consequences of care (positive or negative) for the care-receivers (and ultimately also for the caregivers) are dependent greatly on the caregiving approach. In turn, it is proposed to include the foundations of care as a dimension of care, given that the literature on care for older people has stressed that the provision of care is justified/motivated by different factors, including love, duty, reciprocity, etc. (see Finch and Mason, 1993; Silverstein and Bengtson, 1997). Elaine Brody (2004) argues that the rationale used by the caregivers to justify their involvement in care provision shape the experiences and the meanings of providing (and receiving) care.

In this vein, based on the relevant literature reviewed above, mainly on the conceptual proposals of Thomas (1993), Daly and Lewis (2000) and Tronto (1993, 2013), a new unified definition of care is proposed here. This definition intends to be clear and comprehensive - identifying multiple dimensions of care and some components within each dimension - in order to facilitate its operationalization, the comparative analysis and theory development. The new definition of care, in the context of elder care, is as follows: 
Care is both a disposition and an activity, materialised in a process involving at least one caregiver and one care-receiver, both having their own social identities. Care is intrinsically relational, as it is an action oriented to the other, usually with the ultimate purpose of promoting his/her well-being. The care relationship is based on interconnectedness and interdependence, can be anchored in kinship and/or other kinds of social relations, can take place in the state domain and/or other social domains and in different locations or settings. Care can be founded in love, duty or other rationales and, as an activity, may include different kinds of tasks, which are carried out under certain working conditions and by using a certain approach. The activity of care, as well as the caregiver and the care-receiver, are embedded in contexts of different nature and different level of proximity, which shape the care process, the care practices and the meaning of care for all the actors involved. The consequences of care, for both the caregiver and care-receiver, can be positive or negative. Finally, care can be analysed at the micro, meso and macro level of the reality.

Based on this definition, it is possible to identify fourteen dimensions and some components within each dimension (please see table 1). Considering that this is a complex concept, we recognise that other components may exist (and eventually other dimensions).

While most of the dimensions and components of care do not need further explanations, given that they were previously explained and/or are easily understood, there are some dimensions and components which require an additional explanation. The components "disposition" and "activity", which are included in the dimension "nature of care", correspond to the classic components of the attitudes, namely "cognitive", "affective" and "behavioural". The "disposition" component includes the "cognitive" (think of) and "affective" (feel for) components, whilst the "activity" component includes the "behavioural" (act on) component. However, as suggested by James (1992), the "activity" component of care does not exclusively include physical labour but also organising and planning labour, as well as emotional labour. From the viewpoint of James (1992: 500), "Emotional labour is about action and reaction, doing and being, and can be demanding and skilled work".

In turn, the dimension "social anchorage of the care relationship" refers to the kind of social relation in which the care relationship is anchored. This relationship can be anchored in a kinship relation, in a friendship relation or in a contractual relation. This last social relation includes some kind of formal commitment, not necessarily written in a contract, in which the parts involved are aware that there are some rules and procedures to follow. In this kind of social relation, the provision of care is formally organized, regulated and monitored. The relation between an older individual and a home care service is an illustrative example of a contractual relation.

The component "market", which belongs to the dimension "social domain of care", includes the subcomponents "formal" and "informal". The formal market is the market formally organised, which functions according to certain laws and regulations (e.g., a private-for-profit organisation which provides care for older 
Table 1 Dimensions and components of care

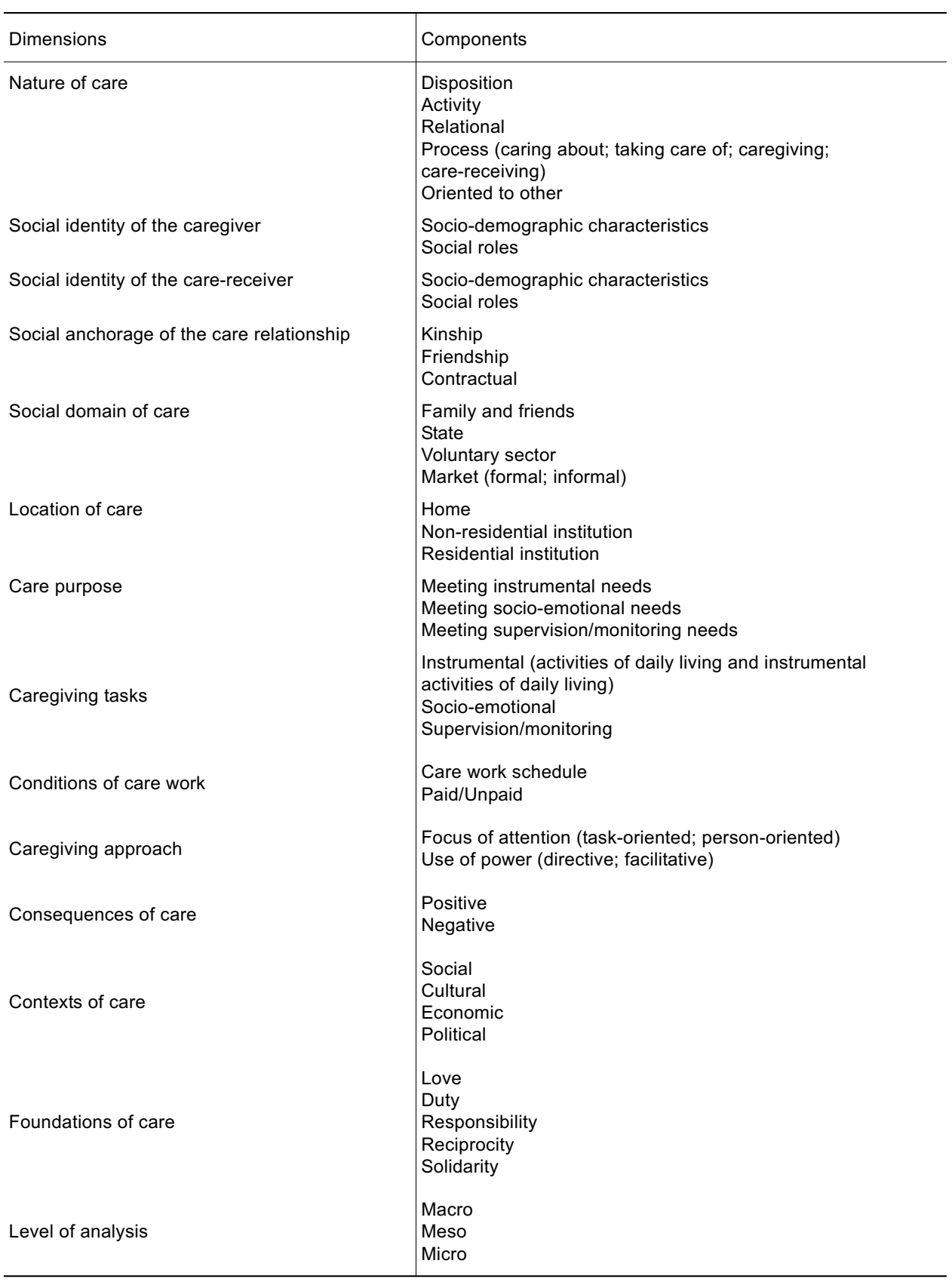


people). Contrarily, the informal market functions outside of any formal framework and regulations (e.g., a migrant providing care in an informal basis).

The components "non-residential institution" and "residential institution", which are inserted in the dimension "location of care", refer, respectively, to institutions which do not accommodate the older individuals during 24 hours a day in a long term basis (e.g. a day care centre), and to institutions which accommodate the older individuals during 24 hours a day in a long term basis (e.g. a nursing home).

Regarding the dimension "caregiving approach", its components derive from the Helping Style Inventory (HIS) developed by Peter VanKatwyk (2003) in the field of family therapy. This instrument uses a double-axis model of two dimensions in order to classify the helping styles. The horizontal axis is the focus of attention dimension which ranges from the task-orientation's focus (focus on the problem) to the person-orientation's focus (focus on the person and the person's life as affected by the problem). The vertical axis is the use of power dimension (also highlighted by Tronto, 2013) which ranges from the directive use of self (emphasis on the strengths of the helper in terms of knowledge, experience and symbolic capital) to the facilitative use of self (emphasis on the strengths of the persons seeking help in terms of their wisdom and experiences). The combination of these two axes produces four quadrants, which identify four helping styles.

Finally, with respect to the dimension "foundations of care", its components derive from the specialized literature which has identified different kinds of foundations, such as love, duty, responsibility, reciprocity and solidarity (Pimentel, 2006; São José, 2009).

It should be mentioned that, despite the fact that this definition was developed having in mind the field of elder care, it is believed that it can be used in other contexts of care.

\section{Suggestions for future research}

At the level of empirical research, many of the research topics introduced during the last decade and a half (described earlier) need further exploration, especially those which appeared more recently. Therefore, it is worth pursuing these topics in the near future.

In turn, at the methodological level, it would be useful to develop, more often, longitudinal or diachronic designs to better understand caregiving/care-receiving over time, as most studies are still based on cross-sectional data. The adoption of a life course perspective and narrative/biographical approaches could be very fruitful for this purpose.

Finally, at the theoretical level, in addition to the potential benefits resulting from the use of an unified concept of care (described earlier), research on care for older people could take advantage of some theories on ageing (e.g. The Life Course Perspective; The Critical Gerontology) in order to explain the research findings and some empirical generalizations. This was highlighted by Thomas (1993: 668) in 
the early 90s when he stated that "Forms of care, and the relationship between them, remain to be theorized in terms of other theoretical categories."

\section{Final thoughts}

The primary aim of this article was to make a contribution to clarify the concept of care (in the field of care for older people), by reviewing and discussing the conceptual literature and, based on this, by proposing a new unified definition. The secondary aim of this article was to trace, in general terms, the evolution of the empirical research on care for older people, presenting at the same time, possible avenues for future research.

It is believed that this article makes an effective contribution to clarify the concept of care and that the new unified definition proposed offers many potential benefits for future research. This definition, and the associated dimensions and components, can be useful for future operationalisations of the concept, promoting in this way a more focused empirical research with greater robustness, reliability and validity. Additionally it is expected that this conceptual review could contribute for a continuous and deeper conceptual discussion of care, a discussion which is long overdue. Finally, it is expected that the broad review of the empirical research undertaken could function as an introduction to the field of care for older people, opening up at the same time new horizons for future research.

\section{References}

Anttonen, Anneli, and Jorma Sipilä (1996), “European social care services: is it possible to identify models?", Journal of European Social Policy, 6 (2), pp. 87-100.

Arber, Sara, and Jay Ginn (1992), "Research note - class and caring: a forgotten dimension", Sociology, 26 (4), pp. 619-634.

Barnes, Marian (2006), Caring and Social Justice, Basingstoke and New York, Palgrave Macmillan.

Barnes, Marian (2012), Care in Everyday Life. An Ethic of Care in Practice, Bristol, The Policy Press.

Brody, Elaine M. (1981), "Women in the middle and family help to older people", The Gerontologist, 21, pp. 471-479.

Brody, Elaine M. (2004), Women in the Middle, New York, Springer Publishing Company ( $2^{\text {nd }}$ edition).

Bryman, Alan (2012), Social Research Methods, Oxford and New York, Oxford University Press (4th edition).

Christensen, Karen, and Ingrid Guldvik (2014), Migrant Care Workers. Searching for New Horizons, Surrey, Ashgate.

Daly, Mary, and Jane Lewis (2000), "The concept of social care and the analysis of contemporary welfare states", British Journal of Sociology, 51 (2), pp. 281-98. 
Finch, Janet, and Dulcie Groves (1983), A Labour of Love. Women, Work and Caring, London, Routledge \& Kegan Paul.

Finch, Janet, and Jennifer Mason (1993), Negotiating Family Responsibilities, London, Routledge. Graham, Hilary (1983), "Caring: a labour of love”, in Janet Finch, and Dulcie Groves (Eds.), A Labour of Love. Women, Work and Caring, London, Routledge \& Kegan Paul, pp. 13-30.

Graham, Hilary (1991), “The concept of caring in feminist research: the case of domestic service", Sociology, 25, pp. 61-78.

Graham, Hilary (1997), “Feminist perspectives on caring”, in Joanna Bornat, Julia Johnson, Charmaine Pereira, David Pilgrim, and Fionna Williams (Eds.), Community Care. A Reader, Basingstoke, Macmillan and Open University, pp. 54-78 ( $2^{\text {nd }}$ edition).

James, Nicky (1992), "Care = Organisation + Physical Labour + Emotional Labour", Sociology of Health E Illness, 14 (4), pp. 488-509.

Jesson, Jill K., Lydia Matheson, and Fiona M. Lacey (2011), Doing Your Literature Review. Traditional and Systematic Techniques, Los Angeles, Sage Publications.

Keith, Lois (1992), "Who cares wins? Women, caring and disability", Disability, Handicap and Society, 7 (2), pp. 167-175.

Knijn, Trudie, and Monique Kremer (1997), “Gender and the caring dimension of welfare states: toward inclusive citizenship", Social Politics, 4 (3), pp. 328-61.

Kong, Eun-Hi, Janet A. Deatrick, and Lois K. Evans (2010), “The experiences of Korean immigrant caregivers of non-english-speaking older relatives with dementia in American nursing homes", Qualitative Health Research, 20 (3), pp. 319-329.

Kröger, Teppo (2009), “Care research and disability studies: nothing in common?" Critical Social Policy, 29 (3), pp. 398-420.

Lewis, Jane (Ed.) (1998), Gender, Social Care and Welfare State Restructuring in Europe, Aldershot, Ashgate.

Lewis, Jane, and Barbara Meredith (1988), Daughters Who Care. Daughters Caring for Mothers at Home, London and New York, Routledge.

Montgomery, Rhonda J. V., Judith C. Gonyea, and Nancy R. Hooyman (1985), "Caregiving and the experience of subjective/objective burden", Family Relations, 34, pp. 19-26.

Montgomery, Rhonda J. V., Donald E. Stull, and Edgar F. Borgatta (1986), “Measurement and analysis of burden", Research on Aging, 7, pp. 137-152.

Morris, Jenny (1995), “Creating a space for absent voices: disabled women's experiences of receiving assistance with daily living activities", Feminist Review, 51, pp. 68-93.

Morris, Jenny (1997), "Care or empowerment? A disability rights perspective", Social Policy \& Administration, 31 (1), pp. 54-60.

Nolan, Mike, Gordon Grant, and John Keady (1996), Understanding Family Care, Buckingham, Open University Press.

Oliver, Michael (1983), Social Work with Disabled People, Basingstoke, Macmillan.

Parker, Roy (1981), “Tending and social policy”, in Elsa M. Goldberg, and Stephen Hatch (Eds.), A New Look at the Personal Social Services, Discussion Paper, 4, London, Policy Studies, pp. 22-44. 
Pearlin, Leonard. I. (1989), "The sociological study of stress", Journal of Health and Social Behavior, 30, pp. 241-256.

Phillips, Judith (2007), Care, Cambridge, Polity Press.

Pimentel, Luísa (2006), A Prestação de Cuidados a Pessoas Idosas Dependentes. Uma Análise das Relações Familiares Intergeracionais e de Germanidade, Lisbon, ISCTE, PhD thesis.

Qureshi, Hazel, and Alan Walker (1989), The Caring Relationship. Elderly People and Their Families, Basingstoke, Macmillan Education.

São José, José de (2009), Cuidar de Um Familiar Idoso Dependente. Trajectórias de Cuidar e Seus Significados, Lisbon, Instituto de Ciências Sociais da Universidade de Lisboa, $\mathrm{PhD}$ thesis.

São José, José de , Rosanna Barros, Sanda Samitca, and Ana Teixeira (2015), “Older persons' experiences and perspectives of receiving social care: a systematic review of the qualitative literature", Health $\mathcal{E}$ Social Care in the Community, DOI: $10.1111 /$ hsc. 12186.

Sevenhuijsen, Selma (1998), Citizenship and the Ethics of Care, London, Routledge.

Silverstein, Merril, and Vern L. Bengtson (1997), "Intergenerational solidarity and the structure of adult child-parent relationships in American families", American Journal of Sociology, 103 (2), pp. 429-460.

The University of Sheffield (2011), Futurage. A Road Map for European Ageing Research, Sheffield, The University of Sheffield.

Thomas, Carol (1993), “De-constructing concepts of care”, Sociology, 27 (4), pp. 649-669.

Tronto, Joan C. (1993), Moral Boundaries. A Political Argument for an Ethic of Care, London, Routledge.

Tronto, Joan C. (2013), Caring Democracy. Markets, Equality, and Justice, New York and London, New York University Press.

Twigg, Julia, Carol Wolkowitz, Rachel L. Cohen, and Sarah Nettleton(2011), "Conceptualising body work in health and social care", in Julia Twigg, Carol Wolkowitz, Rachel Cohen, and Sarah Nettleton (Eds.), Body Work in Health and Social Care. Critical Themes, New Agendas, Coventry, Wiley-Blackwell, pp. 1-18.

Ungerson, Clare (1987), Policy is Personal - Sex, Gender and Informal Care, London, Tavistock.

Ungerson, Clare (1990), Gender and Caring. Work and Welfare in Britain and Scandinavia, London, Harvester Wheatsheaf.

VanKatwyk, Peter L. (2003), Spiritual Care and Therapy - Integrative Perspectives, Waterloo, Wilfrid Laurier University Press.

Wærness, Kari (1984a), “The rationality of caring”, Economic and Industrial Democracy, 5, pp. 185-211.

Wærness, Kari (1984b), “Caring as women's work in the welfare state”, in Harriet Holter (Ed.), Patriarchy in a Welfare Society, Oslo, Universitetsforslaget, pp. 67-98.

Williams, Fiona (2004), Rethinking Families, London, Calouste Gulbenkian Foundation.

Zechner, Minna (2008), "Care of older persons in transnational settings", Journal of Ageing Studies, 22 (1), pp. 32-44. 
José de São José. Professor, Faculty of Economics, University of Algarve, Campus de Gambelas, Edifício 9, 8005-139 Faro, Portugal. E-mail: jsjose@ualg.pt

\section{Acknowledgements}

This paper has been partially supported by the Portuguese Foundation for Science and Technology (FCT).

Receção: 26 de maio de 2015 Aprovação: 12 de novembro de 2015 